\title{
Research on the Influence of Mobile Media on College Ideological and Political Education and Countermeasures
}

\author{
Yingli Yan \\ Nanyang Institute of Technology, Nanyang, Henan, 473000, China
}

Keywords: Mobile Media; Colleges; Ideological and Political Education; Influence

\begin{abstract}
The development and popularization of smart phones has promoted the integration of mobile phone clients and the Internet. Mobile media has emerged as the times require. Compared with traditional media, the advantages of mobile media are obvious. However, as a new medium, mobile media has changed not only the form, but also the advantages of various media. It is the unity of traditional media and new media in a certain sense. In this context, the ideological and political education of colleges and universities has ushered in unprecedented opportunities and challenges. College students' dependence on mobile phones is getting higher and higher. The influence of mobile media on college students' outlook on life, values and world outlook is also growing. If they are not properly guided, bad information on mobile media may have life, growth and even future for college students. Development has a negative impact. Therefore, it is necessary to face the influence of mobile media in the ideological and political education of colleges and universities and take effective intervention measures.
\end{abstract}

\section{The Positive Impact of Mobile Media on Ideological and Political Education in Colleges and Universities}

Specifically, the positive impact of mobile media on ideological and political education in colleges and universities is mainly reflected in the following aspects:

First, it has innovated the concept of ideological and political education. Traditional ideological and political education is limited to small classrooms, students are in a passive learning position, and the knowledge they teach is limited to textbooks. The emergence of mobile media has expanded the scope of ideological and political, and innovated the concept of teachers and students on ideological and political education. Mobile media can enhance the self-awareness of college students. The new era of college students has distinct personality and strong self-respect. Ideological and political educators must keep up with the times, understand the students' ideological characteristics, and innovate their own educational concepts. In addition, mobile media has greatly improved the convenience of students to obtain ideological and political information. Mobile media is the integration of various media. It is very convenient for students to obtain ideological and political information, and the communication and interaction between teachers and students is more efficient, which is conducive to the creation of a democratic teacher-student relationship. Second, innovative ideological and political education means. Nowadays, smart phones have very powerful functions. Some chat softwares increase the convenience of communication between students and teachers. Ideological and political educators use these functions to communicate and interact with students, and can teach students the value of ideological and political education anytime and anywhere. Content; and the form of teaching is also more diverse. Smartphones support pictures, texts, videos and other forms of information, which are more in line with the psychological characteristics of students, and students are more acceptable. Finally, the students' self-educational awareness is continuously strengthened. Modern college students have independent thoughts and strong desire for knowledge. They will show higher enthusiasm for some new things. Mobile media can help students to browse a large amount of information. Students need to identify themselves when collecting information, eliminate invalid information, and retain useful information. The process is precisely the process of self-education and self-learning. Students actively and actively digest and understand the information provided by mobile media according to their own needs, and 
internalize them into their own ideas and knowledge systems.

\section{The Negative Impact of Mobile Media on Ideological and Political Education}

In the ideological and political education of colleges and universities, mobile media is a double-edged sword. It not only brings new opportunities for ideological and political education in colleges and universities, but also makes ideological and political education face unprecedented challenges, which are manifested in the following aspects:

First of all, college students are over-reliant on mobile media. Excessive reliance of college students on mobile media will lead to a certain degree of personality splitting and will create barriers to interpersonal communication. The smart phone is powerful, including the camera, alarm clock and other mobile phone functions, and can download various third-party applications through the mobile network. Too much reliance on mobile phones will directly affect their personal emotions, such as anxiety and loss of appetite, as well as problems such as inattention and loss of interest in life. Moreover, mobile media mainly communicates through virtual communication, which weakens students' ability in real life. The more students are not good at interpersonal communication, the more they rely on virtual communication of mobile phones. Over time, they enter a vicious circle and lead students to appear. Second, it will have a negative impact on the values of college students. The information dissemination of mobile media has a strong timeliness. Some students with political awareness, weak sense of responsibility and poor self-discipline will be affected by bad information and act as recipients and communicators. This is an ideological and political education and advocacy. The mainstream values are very unfavorable. Finally, it weakens the role of the main body of education. The development of mobile media is changing with each passing day. In the process of mass information dissemination, the information identification ability of college students is weak. If it is affected by bad information, it will lead to moral decline and confusion of values. Some ideological and political teachers are influenced by traditional concepts. The media lacks correct cognition, fails to fully understand the role of mobile media, and cannot adapt to the new information environment. It is also impossible to actively apply mobile media in the practice of ideological and political education. In addition, the mobile phone media blurs the boundaries of the main body of communication, and the channels for students to obtain information are more and more abundant. The mobile media can have a self-education effect on students, weakening the decision-making power of traditional school education on information, and leading to the authority of school education subjects.

\section{The Strategy of Improving the Effectiveness of Ideological and Political Education in the Mobile Media Environment}

Mobile media is a double-edged sword for college ideological and political education. Under the new situation and new environment, college ideological and political education should be based on reality, recognize the current situation, and combine ideological and political education with the characteristics of the mobile media environment:

Mobile media is based on network technology. To use mobile media to conduct ideological and political education, it is necessary to improve relevant hardware support to fully utilize the advantages of mobile media. First of all, it is necessary to improve the network hardware facilities in the school, build a perfect free wifi system in the school, improve the convenience of using mobile media in ideological and political education, and improve the efficiency of ideological and political education. Second, use mobile media to explore new ways of education. College students using mobile phones to browse the web has become a part of their lives. College ideological and political teachers can develop "red" mobile phone websites based on mainstream values and set up ideological and political related content sections, such as national major guidelines and policies, advanced moral figures on campus, and party History, etc., allows students to accept ideological and political education while browsing the website. Finally, develop the "red" app. APP refers to third-party application software installed in the mobile phone system, and is also a popular 
smartphone tool for students. College ideological and political education workers can develop "red" APP under the guidance of mainstream ideology and the actual situation of college students. The content is mainly based on mainstream values, while the design and application experience are more concerned with the actual needs of students. For example, you can introduce red tourist attractions in the APP, and you can also set up prizes to participate, such as sending tourist attractions tickets, tourist souvenirs, etc., to improve the appeal of APP to students.

On the one hand, ideological and political teachers in colleges and universities should constantly improve their professional theories, strengthen the study of theoretical knowledge, and carefully interpret the core values of socialism. The school can regularly invite some experts and scholars to the school to give lectures, ideological and political teachers, some student representatives to participate in lectures to improve their professional theory. The school can also create a good ideological and political education atmosphere in the school, such as the establishment of the school ideological and political academic forum, which can not only improve the utilization efficiency of the school's teaching resources, but also enhance the connection between the relevant colleges and provide a good platform for teachers to conduct theoretical discussions. Finally, promote the development of the overall ideological and political education level of the school. On the other hand, ideological and political teachers must further improve their information quality. Under the mobile media environment, the information quality of ideological and political teachers will have a direct impact on the effect of ideological and political education. Therefore, teachers should establish a keen sense of information and improve the consciousness of capturing information, collecting information and analyzing information. Only the teacher's own information is identified. The ability to be higher than students can further establish the authority of mainstream education in ideological and political education. In addition, ideological and political teachers should also upgrade their information ethics, absorb the essence of the traditional Chinese ethics, and integrate excellent traditional culture into modern ideological and political education. The development of mobile media has greatly improved the efficiency of information dissemination. Teachers can send ideas of different genres to students through text, pictures, voice and video to guide students to establish a high level of information ethics.

First, set up a messaging platform. Mobile phones are a new type of communication tool. Students are more and more dependent on mobile phones. They usually get all kinds of important information or news through mobile phones for the first time. Therefore, teachers can enrich the media direction through the establishment of SMS platform. The communication platform realizes the integration of information to improve the convenience of information exchange between teachers, teachers and students, and between students; and the SMS platform can also send information in groups, teachers optimize the content of ideological and political education, and then through targeted Sexual and selective mass information not only improves the effectiveness of information transmission, but also creates a good atmosphere of ideological and political education. Second, establish a sound monitoring system. Mobile media not only has a wide range of coverage, but also has a wide coverage. The students are almost one-handed. With the support of Internet technology, the efficiency of media resources is greatly improved. However, the information disseminated by mobile media is mixed. If the supervision is not strengthened, it will have a negative impact on students' ideological and political training. Therefore, teachers should establish a perfect mobile phone information monitoring system to standardize the information transmission behavior of students, so as to ensure that students can be accurate. Efficiently accepting ideological and political knowledge and being able to form correct values. Finally, use mobile media to establish an effective communication link to conduct real-time mental health counseling for students. Mobile media has shortened the time and space distance of ideological and political education situations, and with the support of network technology, it has improved the timeliness and effectiveness of network resource transmission. Ideological and political teachers should give full play to the advantages of mobile media, break the limitations of traditional teaching modes, use various mobile real-time communication tools to communicate with students, timely understand the students' ideological dynamics, build an effective psychological communication platform, and 
improve ideological politics. The affinity of education closes the distance between teachers and students, and ultimately achieves the purpose of improving the effectiveness of ideological and political education.

\section{Conclusion}

In short, the influence of mobile media in college ideological and political education is both positive and negative. Its advantages in innovative ideological and political education concepts and means are outstanding, which enhances students' self-educational awareness, but college students on mobile media Over-reliance will have a negative impact on the values of college students, and will weaken the role of the main body of education. Therefore, teachers should face up to the role of mobile media in ideological and political education, actively guide students to seek advantages and avoid disadvantages, and constantly improve the media literacy of college students. Give play to the positive role of mobile media in ideological and political education, guide students to establish a correct outlook on life, values, and world outlook, improve the effectiveness of ideological and political education in colleges and universities, and finally achieve the goal of ideological and political education.

\section{References}

[1] Lu Jie, Xu Jing. The Influence of the Media Age on the Ideological and Political Education Work in Colleges and Universities and Its Coping Strategies [J]. Journal of Shandong Youth Politics College, 2018, 29(2): 72-76.

[2] Chen Zhipeng. Shao Kaixuan. The Influence of New Media on College Students' Ideological and Political Education and Countermeasures[J].Journal of Chifeng College(Natural Science), 2014, (01)196-197.

[3] Zhang Yupeng, Meng Yue. Analysis of the Path of Mobile Media in the Management of College Students' Ideological and Political Education [J]. Journal of Jilin College of Education, 2018, (5): 83-84.

[4] Xu Xiaopeng, Huang Jixin. Exploring the Path of Developing College Students' Ideological and Political Education by Using Campus Mobile Newspapers [J]. Education Theory and Practice, 2017, (27): 79-80.

[5] Lin Wen. The Exploration and Practice of Mobile Phone Short Messages to Carry out College Students' Ideological and Political Education_— Taking the Theme Education of Fujian Institute of Technology as an Example[J].Journal of Huanggang Normal University, 2017,(5):100-101.

[6] Zhu Jian, Yan Mengjun. The Influence and Countermeasure of "Thumb Culture" on College Students' Ideological and Political Education [J]. Thought Education Research, 2010, (12): 95-97.

[7] Cheng Wenzhong. The Influence of Mobile Culture on College Students' Mainstream Ideology and Countermeasures [J]. Journal of Fuzhou University (Philosophy and Social Sciences), 2010, (2): 109-110. 